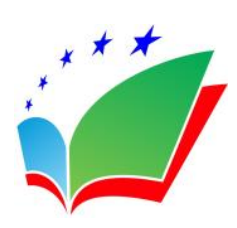

European Journal of Fitness, Nutrition and Sport Medicine Studies

ISSN: $2668-9758$

ISSN-L:2668 - 9758

Available on-line at: $\underline{\text { www.oapub.org/hlt }}$

DOI: 10.46827/ejfnsm.v3i1.113

Volume 3 | Issue 1 | 2022

\title{
NUTRITION ERGOGENIC SUPPLEMENTS REGULATE BLOOD PH. - AN UPDATE
}

\author{
Konstantinos D. Tambalis ${ }^{i}$, \\ Giannis Arnaoutis \\ Department of Nutrition and Dietetics, \\ School of Health Science \& Education, \\ Harokopio University, \\ Athens, Greece
}

\begin{abstract}
:
Ergogenic nutritional supplements are a type of sports food. Sodium bicarbonate and balanine are two of the most popular and legally permitted ergogenic dietary supplements. These two chemicals have a comparable ergogenic effect because they help to neutralize hydrogen cations created during anaerobic glycolysis during exercise. The hydrogen ions will exit the trained muscles faster if the extracellular regulatory capacity of the organism is increased by strengthening the stores of bicarbonate ions. And before the acidification within the muscle cells becomes a limiting factor of athletic performance, more hydrogen ions and lactic acid will be produced. The goal of this review is to go over the two most common dietary supplements, sodium bicarbonate and b-alanine, that have been shown to improve athletic performance by neutralizing hydrogen cations created during anaerobic glycolysis during exercise. Sodium bicarbonate and b-alanine are legal ergogenic aids that are inexpensive and simple to make, and they have been used by athletes for decades. The extracellular mechanism of "neutralization" of hydrogen ions that build in the exercised muscle is aided by sodium bicarbonate consumption, which increases bicarbonate concentrations in the blood. The ideal dose is between 0.3 and 0.5 grams per kilogram of body weight, and it should be consumed 150-180 minutes before exercise to minimize or lessen gastrointestinal problems. B-alanine supplementation can also improve anaerobic exercise performance, with a more apparent effect in trials lasting 1 to 4 minutes at high intensity, whereas its ergogenic effect appears to be minimal to moderate in exercises lasting up to 25 minutes. Furthermore, it improves the volume of resistance training; yet, increasing strength has no added advantage. Carnosine reserves in muscle are greatly increased after 4 weeks of administration (4-6 gr/day), operating as an intramuscular mechanism for controlling $\mathrm{H}^{+}$concentration. Furthermore, a loading dose of 4-6 grams per day in doses of 2 grams or fewer is necessary for a least of 2 weeks,
\end{abstract}

'Correspondence: email dp425603@hua.gr 
with a larger benefit after 4 weeks. Paraesthesia is the sole negative effect at the prescribed levels (tingling).

Keywords: sodium bicarbonate, $\beta$-alanine, exercise, athletic performance, alkalosis

\section{Introduction}

Athletes primarily consume sports foods and nutritional supplements in the hopes of gaining benefits such as (a) promoting training adjustments; (b) increasing energy reserves; (c) continuing more effective and intensive training by promoting recovery between sessions; (d) maintaining good health and reducing "lost" training due to chronic fatigue, illness, or injury; (e) improving competitive performance; and (g) reducing "lost" training due to chronic fatigue, illness, or injury (Burke \& Deakin V, 2006). The last is the most prevalent reason for athletes to consume sports meals before, during, or after an exercise (Burke \& Deakin V, 2006). Ergogenic nutritional supplements are a type of sports food. Sodium bicarbonate and -alanine are two of the most popular and legally permitted ergogenic dietary supplements (Spriet, Perry \& Talanian, 2008). These two chemicals have a comparable ergogenic effect because they help to neutralize hydrogen cations created during anaerobic glycolysis during exercise (Tambalis, 2017).

Sodium bicarbonate $\left(\mathrm{NaHCO}_{3}\right)$ is a white, crystalline substance that is commonly encountered as a fine powder. It has a slightly alkaline flavour and is also synthesized. It is well-known and can be found under a variety of names, including baking soda, bicarbonate of soda, and so on. Sodium bicarbonate is an alkaline salt found in the body whose major role is to assist in controlling conditions of elevated acidity by functioning as a regulatory agent for the body's acids. It is also known as a regulatory salt because of this (Brody T, 1999). Sodium bicarbonate is a common nutritional ergogenic supplement used in sports; it is widely available and easy to obtain (Tambalis, 2017).

B-alanine (also known as 3-aminopropanoic acid) is a naturally occurring -amino acid that is not required for the production of any significant protein or enzyme. It produces peptides like carnosine, anserine, and pantothenic acid (vitamin B5), all of which are components of coenzyme A. In skeletal muscle, b-alanine is coupled with histidine to generate the carnosine dipeptide (Hoffman, Emerson \& Stout, 2012). The major purpose of b-alanine administration is to aid in the formation of muscle carnosine in the sarcoplasm of human skeletal muscle when combined with 1-histidine. Carnosine synthesis is restricted by the amount of -alanine in plasma that can be delivered to muscle sarcoplasm since endogenous 1-histidine is easily accessible and abundant (Brody T, 1999). Stellingwerf et al. (2012) conducted a study of b-alanine administration protocols and found that the subsequent increase in muscle carnosine concentration is dependent on the total amount of b-alanine consumed rather than the initial intramuscular storage.

The $\mathrm{pH}$ of the arteries in the normal functioning of the human body (rest) is 7.4, (slightly alkaline), while the $\mathrm{pH}$ of the muscles is 7.0. The arterial $\mathrm{pH}$ can drop to 7.1 after hard exercise, while the muscle $\mathrm{pH}$ reduces to 6.8. To maintain homeostasis, the body maintains a balance between the generation and removal of hydrogen cations by the 
following basic mechanisms of acid-base balance regulation: (a) chemically regulates the balance of $\mathrm{H}+$ in seconds? (b) by pulmonary ventilation and $\mathrm{H}+$ secretion, and (c) on a long-term basis through renal $\mathrm{H}+$ secretion to maintain acid-base balance (ACSM, 2006). Anaerobic glycolysis is the primary source of energy for physical activities that are nearly maximal (85\% VO2max) and lasts longer than 30 seconds. The steady increase in acidity (down in $\mathrm{pH}$ ) within the muscle, which is caused by the concentration of lactic acid and hydrogen ions, limits the system's total capacity (Caspersen, Powell \& Christenson, 1985). Muscle acidity causes energy transmission and muscle contraction to be inhibited, resulting in lower sports performance (ACSM, 2006). Bicarbonate ions are part of the body's regulatory system and serve as the first line of defence against excessive acidity in the tissues. Lactic acid and hydrogen ions diffuse into the extracellular space, i.e. outside the cells, when the acidification inside the cells surpasses the cells' regulating capability (Lancha, Painelli, Saunders \& Artioli, 2015). Based on the foregoing, improving the body's extracellular regulatory capability by strengthening bicarbonate ion reserves will allow hydrogen ions to escape the trained muscles more quickly (Burke LM, 2013). And before the acidification within the muscle cells becomes a limiting factor of athletic performance, this will result in the formation of additional hydrogen ions and lactic acid (Burke LM, 2013).

The involvement of sodium bicarbonate and b-alanine in the regulation of blood $\mathrm{pH}$ during exercise has been largely ignored, despite the fact that both chemicals alter $\mathrm{pH}$ and acid-base balance, and thus athletic performance.

The goal of this review is to go over the two most common dietary supplements, sodium bicarbonate and b-alanine, that have been shown to improve athletic performance by neutralizing hydrogen cations created during anaerobic glycolysis during exercise.

\section{Methods}

Studies for this narrative review were found primarily through a systematic search of the electronic databases MEDLINE, PubMed, and EMBASE, using terms, title words, and abstract words such as "exercise", "physical activity", "athletes", "athletic performance", "nutrition supplements", "ergogenic aids", "bicarbonate sodium" and "b-alanine." We also employ past review articles, as well as references from original studies and related books, in our computer analysis. Physical activity, athletic performance, exercise, health, bicarbonate sodium, and b-alanine were all used as keywords. We looked for studies that used the above terms and were published in the English language between January 1985 and December 2021. Studies were considered if they offered information on bicarbonate sodium or b-alanine consumption in athletes, evaluated their potential efficacy in terms of athletic performance and/or health, or detailed the mechanism of action, administration procedures, safety, and recommendations. Each qualified article's title and abstract were examined, and full-text articles were retrieved in circumstances where inclusion was in doubt. 


\section{Bicarbonate Sodium}

When metabolism produces an acid such as lactic acid, which is much more potent than carbonic acid, a proton is released, binds to bicarbonate, and forms sodium lactic and carbonic acid. Eventually, carbon dioxide and water are formed from this chemical reaction. The following steps describe the processes that affect the regulatory systems in the blood during exercise. Hemoglobin carries $\mathrm{O}_{2}$ from the lungs to the muscles through the blood. Muscles need more $\mathrm{O}_{2}$ than normal because their metabolic activity increases during exercise. The amount of oxygen in the muscle is therefore depleted, and a difference in concentration is created between the muscle cells and the blood in the capillaries. Oxygen diffuses from the blood to the muscles through this difference in concentration. Muscles produce $\mathrm{CO}_{2}$ and $\mathrm{H}^{+}$, as a result of increased metabolism, which leaks from the muscles into the bloodstream through the difference in concentration between them. The regulatory action of hemoglobin absorbs the extra $\mathrm{H}^{+}$and $\mathrm{CO}_{2}$. When the amounts of $\mathrm{H}^{+}$and $\mathrm{CO}_{2}$ exceed their ability to be absorbed by hemoglobin, this results in a decrease in blood $\mathrm{pH}$, causing acidosis (ACSM, 2016; Carr, Hopkins \& Gore, 2011). The lungs and kidneys respond to changes in $\mathrm{pH}$ by removing $\mathrm{CO}_{2}, \mathrm{HCO}_{3}$, and $\mathrm{H}^{+}$from the blood. As a result, the body has developed subtle coordinated chemical processes (based on $\mathrm{pH}$ and acid-base balance) that work together to handle the changes, and in particular, the increased hydrogen cations production that exercise brings (Carr, Hopkins \& Gore, 2011).

The normal supply of bicarbonate in the blood helps to delay the onset of fatigue during intense anaerobic exercise. However, fatigue is unavoidable if the rate of lactic acid production exceeds the regulatory capacity of the body's bicarbonate stores as mentioned above (Hollidge-Horvat et al., 2000). Thus, in theory, increasing the body's bicarbonate levels, through the intake of sodium bicarbonate, could delay the onset of fatigue. The administration of sodium bicarbonate before intense exercise reduces the $\mathrm{H}^{+}$of the blood and in this way possibly helps the outflow of $\mathrm{H}^{+}$from the muscle and mitigates the metabolic acidity in the muscle (Hollidge-Horvat et al., 2000).

Due to the previous negative effects of muscle acidity, it has been hypothesized that: (a) induction of pre-exercise alkalization; (b) strengthening of muscle cell regulatory systems, and; (c) increased ability to remove hydrogen ions, would have beneficial effects on the appearance of fatigue and therefore in the improvement of athletic performance. That is, the increased potency of the extracellular buffer $\left(\mathrm{NaHCO}_{3}\right)$ would facilitate the exit of $\mathrm{H}^{+}$from the functioning muscle cells and thus delay the fall of the intracellular $\mathrm{pH}$ and its negative consequences on muscle function (Car et al., 2011).

\subsection{Effect of $\mathrm{NaHCO}_{3}$ on Athletic Performance}

This section will present selected scientific studies on the effect of sodium bicarbonate on various parameters of exercise, a summary of studies that did not record a positive effect of the substance on exercise, as well as studies that investigated the effect of the substance in combination with other ergogenic supplements in athletic performance. 
Among the sports in which athletes could benefit from the administration of the substance are sports activities that require high-intensity exercise lasting 1-7 min, such as rowing, swimming, and running distances, and sports lasting 30-60 min of prolonged exercise, just below the anaerobic threshold, in case the athlete's support is aimed at periods of increasing pace, e.g. in the final sprint before the finish. Similarly, athletes who participate in repetitive team sprints and tennis, and possibly martial arts (e.g. boxing, etc.) could also benefit (Car et al., 2011).

In a primary study (Katz et al., 1984) conducted on the effect of the substance on athletic performance, 8 healthy men performed two tests (cycling) until exhaustion one hour after they were given $0.2 \mathrm{gr} / \mathrm{kg}$ of body weight $\mathrm{NaHCO}_{3}$. According to the results of this protocol, alkalosis does not help to prolong an intense exercise session until exhaustion. In contrast, a study by Price et al. (2003) in 8 male volunteers given $0.3 \mathrm{gr} / \mathrm{kg}$ of body weight $\mathrm{NaHCO}_{3}$ or placebo $(\mathrm{NaCl}) 60$ minutes before exercise (cycling) showed that despite the decrease in $\mathrm{pH}, \mathrm{NaHCO}_{3}$ intake is not prevented, its intake provides a more alkaline environment that is maintained during prolonged intermittent exercise compared to control and prevents metabolic acidosis, while, the maximum work output produced by the group consuming $\mathrm{NaHCO}_{3}$ was at higher levels. Another study by Hollidge-Horvat et al., (2000) investigating the effect of alkalosis on muscle metabolism in moderate-intensity exercise in 8 healthy volunteers concluded that $\mathrm{NaHCO}_{3}$ administration contributed to the higher intramuscular lactic acid concentration (alkalosis $72 \mathrm{mmol} / \mathrm{kg}$ dry wet tissue vs. control $65.2 \mathrm{mmol} / \mathrm{kg}$ dry wet tissue) and in the blood (alkalization 8.7 vs. control $7.0 \mathrm{mmol} / \mathrm{l}$ ), increased glycogen utilization and an increased ability of athletes to perform muscle work (cycling) at $60 \%$ and $75 \%$ of $\mathrm{VO}_{2}$ max.

In a study designed to investigate the effect of alkalosis on exercise until exhaustion (wrist flexion) in healthy male volunteers, the results showed that time to exhaustion and peak power increased by $12 \%$ compared to the control group (Raymer, Marsh, Kowalchuk \& Thompson, 2004). Also, a study examining the effect of alkalosis (Edge, Bishop \& Goodman, 2006) on increased endurance exercise (cycling) in 16 amateur women reported that women given $\mathrm{NaHCO}_{3}$ exercised longer in the test until exhaustion. Similarly, in studies by Siegler et al., 2010 \& Lindh et al., 2008 in which participants were male \& female high-level swimmers, the results showed that the performance time was improved by $2 \%$ $\& 1.5 \%$, respectively, compared to the placebo group. In another study by Siegler et al., 2010 involving 10 male amateur boxers, it was found that overall hits were significantly higher in the $\mathrm{NaHCO}_{3}$ test compared to placebo. Finally, a study (Carr et al., 2012) investigated the administration of $\mathrm{NaHCO}_{3}$ in resistance exercise (muscle hypertrophy) the authors concluded that the administration of the substance may have ergogenic effects in the resistance exercise.

According to Stellingwerff et al., (2007), in a meta-analysis of 29 studies on the effect of sodium bicarbonate on athletic performance, $\mathrm{NaHCO}_{3}$ resulted in a performance effect size that was 0.44 standard deviations better than the control group. Improving the standard deviation of 0.44 if translated into $800 \mathrm{~m}$ road performance time could bring the year 2006 to the $800 \mathrm{~m}$ men's average in the Golden League an improvement from 1:46.36 to $1: 45.52$, which is a significant improvement. 
Although a recent meta-analysis by McNaughton et al., (2016) concluded that the benefits of substance use are more pronounced in trained individuals, on the other hand, there have been several studies in recent years that have shown that $\mathrm{NaHCO}_{3}$ administration did not have significant differences in trainees' performance. The following table lists some such surveys.

Table 1: Indicative studies that did not record a significant effect of $\mathrm{NaHCO}_{3}$ administration, in elite athletes

\begin{tabular}{|l|c|c|c|}
\hline Study & Sport & Participants & Effect in athletic performance \\
\hline Tan et al., 2010 & Water polo (female) & Elite & None \\
\hline Driller et al., 2013 & Rowing (male) & Elite & None \\
\hline Kupcis et al., 2012 & Rowing (male) & $\begin{array}{c}\text { Light bodyweight } \\
\text { elite }\end{array}$ & None \\
\hline Joyce et al., 2012 & Swimming (male) & $200 \mathrm{~m}$. elite & None \\
\hline Zabala et al., 2011 & Biking (male) & BMX elite & None \\
\hline Cameron et al., 2010 & Rugby (male) & Elite & \\
\hline
\end{tabular}

Among the possible causes for which no significant effect of $\mathrm{NaHCO}_{3}$ was recorded in the above research were: the design of the research, the very nature of the sport due to which a very high involvement of anaerobic glycolysis was not recorded the high intraindividual variability in its effect administration, etc.

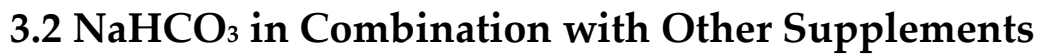

Although sodium bicarbonate is usually marketed as a standalone product, it is often consumed in combination with other nutrients, with the most common combinations being alanine bicarbonate and caffeine bicarbonate.

In a well-designed study by Sale et al., (2011), in 20 young men, the results showed that time to exhaustion (cycling at $110 \%$ of maximum strength) increased by $12 \%$ in the $\beta$ alanine group and $16 \%$ in the alanine $+\mathrm{NaHCO}_{3}$ group. According to the researchers, although the combination of $\beta$-alanine $+\mathrm{NaHCO}_{3}$ increased by $4 \%$ the depletion time compared to $\beta$-alanine, this was not significant $(p=0.74)$. Further analysis by the researchers suggests that $70 \%$ of the positive difference is due to $\mathrm{NaHCO}_{3}$. In a relatively recent study by Kilding et al., (2012), in 10 well-trained cyclists who performed a timed maximum cycling test $3 \mathrm{~km}$, after administration of either caffeine, $\mathrm{NaHCO}$, placebo, or caffeine $+\mathrm{NaHCO}_{3}$, the results showed that performance was improved over placebo by $2.4 \%, 2.6 \%$ and $2.7 \%$ in the caffeine, $\mathrm{NaHCO}_{3}$, and caffeine $+\mathrm{NaHCO}_{3}$ groups. Moreover, the authors speculated that although caffeine $+\mathrm{NaHCO}_{3}$ administration contributed to higher performance, it did not appear to be cumulative, and that co-administration of both ergogenic aids was probably no longer effective.

In conclusion, the consumption of sodium bicarbonate $(300 \mathrm{mg} / \mathrm{kg}$ Body Weight) 1-2 hours before exercise), can temporarily increase the concentrations of bicarbonate in the blood, enhancing the extracellular mechanism of "neutralization" of hydrogen ions that accumulate and flow from the exercised muscle. This loading protocol provides an ergonomic strategy for sports that require high levels of anaerobic glycolysis but the 
results of which (increased hydrogen cations production) limit the body's ability to manage the progressive increase in intracellular acidity. Studies show that sodium bicarbonate loading strategies have a moderately positive effect on athletic performance in sports involving 1-7 minutes of continuous intense exercise, and may also be useful in long-term sports containing intermittent or prolonged periods of high-intensity exercise. This potential for enhanced athletic performance requires further investigation, using appropriately designed research (Burke L., 2013).

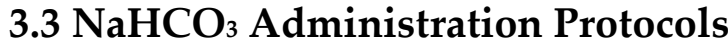

A study (Siegler et al., 2010) in 8 young male volunteers (without exercise), compared the effect of 3 different administration protocols $(0.3 \mathrm{gr} / \mathrm{kg}, 0.2 \mathrm{gr} / \mathrm{kg}, 0.1 \mathrm{gr} / \mathrm{kg}$, and placebo) and at three different times (in the morning, in the afternoon or 3 evening doses), in the $\mathrm{H}^{+}$content of the blood (blood buffering) 120 minutes after administration. According to the results, no significant differences in the $\mathrm{H}^{+}$content of the blood were found between the doses of $0.3 \mathrm{gr} / \mathrm{kg}$ and $0.2 \mathrm{gr} / \mathrm{kg}$, while it was significantly lower at the dose of 0.1 $\mathrm{gr} / \mathrm{kg}$. It also appeared that the morning single dose resulted in a higher $\mathrm{H}^{+}$content of the blood compared to the single afternoon and evening doses. In conclusion, the dose of 0.2 $\mathrm{gr} / \mathrm{kg} \mathrm{NaHCO}$ is better to consume 40-50 min before exercise while the single dose of 0.3 $\mathrm{gr} / \mathrm{kg}$ is $60 \mathrm{~min}$ before exercise. Finally, a meta-analysis of 59 studies in which $0.3 \mathrm{gr} / \mathrm{kg}$ $\mathrm{NaHCO}_{3}$ was the most common dose concluded that the mean improvement in yield was $1.7 \pm 2.0 \%$ for $\mathrm{NaHCO}_{3}$, no improvement was observed in the studies using $0.5 \mathrm{gr} / \mathrm{kg}$ sodium citrate, while a reduction in yield of $1.6 \%$ was observed in the studies that used $0.3 \mathrm{gr} / \mathrm{kg}$ ammonium chloride.

According to current scientific knowledge, the predominant charging protocol for short-term and high-intensity sports, with $\mathrm{NaHCO}_{3}$, includes administration of $0.3 \mathrm{gr} / \mathrm{kg}$, 60-90 $\mathrm{min}$ before exercise or administration of $5 \mathrm{gr} / 2$ times a day for 5 days. This protocol is an effective way to regulate muscle acuity during high-intensity exercise. It can also improve the ability to exercise in activities such as e.g. the 400-800 m running or the 100$200 \mathrm{~m}$ swimming.

\subsection{Acute vs. Multi-day Administration of $\mathrm{NaHCO}_{3}$}

Given that some people have severe gastrointestinal problems due to $\mathrm{NaHCO}_{3}$ administration; athletes need to experiment with training that includes daily continuous races, as most problems occur after a race (semi-final), which can limit performance in each subsequent match (final). Studies have shown more favourable results in gastrointestinal tolerance after chronic multi-day use than the immediate (before the race) single dose. Performance may be enhanced by the effect of the substance even if its chronic administration has been discontinued 2 days before the race, which may bypass the side effects of immediate pre-race administration.

\subsection{Safety and Side Effects}

According to the researchers, even with the consumption of small doses of bicarbonate, the following have been observed: (a) gastrointestinal disorders (b) vomiting, (c) severe 
stomach pain, and (d) diarrhea, especially in people prone to gastrointestinal problems. A study examined the effect of substance administration on gastrointestinal discomfort in 8 men who performed on a floor ergometer 3 sets of 10 sprints of 10 sec each, with an active break of $50 \mathrm{sec}$ while they were consumed $0.3 \mathrm{gr} / \mathrm{kg} \mathrm{NaHCO}$, $60 \mathrm{~min}, 120 \mathrm{~min} \&$ $180 \mathrm{~min}$ before exercise and evaluated blood $\mathrm{H}^{+}$content, mean velocity, potency, and gastrointestinal discomfort found that the ergogenic effects (mean velocity, potency) of $\mathrm{NaHCO}_{3}$ did not differ between protocols, i.e. between administration of the substance 1, 2 or 3 hours before exercise and also that gastrointestinal discomfort was significantly lower $(\mathrm{p}<0.05)$ when $\mathrm{NaHCO}_{3}$ was consumed 180 min before exercise (Carr, Slater, Gore, Dawson \& Burke, 2011). The study concludes that $\mathrm{NaHCO}_{3}$ administration 3 hours before exercise reduces gastrointestinal discomfort.

\subsection{Recommendations}

- Sodium bicarbonate has a moderately positive effect on performance in sports of continuous intense exercise lasting 1-7 minutes, in prolonged sports (30-60 min) which include breaks or prolonged periods of high-intensity prolonged exercise, just below the anaerobic threshold, in case that the athlete's support targets periods of rhythm growth, e.g. in the final sprint before the finish, but also in high-intensity skill sports. Similarly, in repetitive team sports sprints and tennis, and possibly in martial arts (e.g. boxing, etc.).

- These benefits appear to be more pronounced in trained individuals. Nevertheless, there appears to be high intra-individual variability in response to $\mathrm{NaHCO}_{3}$ administration, and therefore ergogenic benefits may not be induced during each exercise period.

- Current scientific knowledge also shows that the athlete must individualize the time of intake to maximize blood bicarbonate and thus maximize the effect on performance. This can enable individuals to achieve the ergogenic benefits of $\mathrm{NaHCO}_{3}$ more consistently.

- It is not dangerous, but especially in sensitive athletes, it causes significant gastrointestinal disorders and its taste is bad.

- It is recommended to take it with a light carbohydrate meal.

- Sodium bicarbonate does not work wonders, but it does improve performance in seconds rather than minutes (Kreider et al. 2010; Peart et al., 2012; Grgic et al., 2021).

\section{B-alanine}

\subsection{B-alanine-carnosine}

Carnosine is a dipeptide composed of alanine and histidine and is found in high concentrations in skeletal muscle. It participates in the reconstruction of the tissues and muscles of the body and is considered a powerful antioxidant (Brody T, 1999). During anaerobic glycolysis, it prolongs the production of lactic acid and consequently muscle cadaver, as it binds to part of the hydrogen cations produced in this process (Lancha et al., 2015). It is often used by athletes to improve their performance, performing a role 
essentially similar to that of sodium bicarbonate. Carnosine normally has a small contribution to the total regulatory capacity of the hydrogen cations produced in a cell. However, beta-alanine administration increases intracellular carnosine concentrations which in turn can improve a muscle's ability to "neutralize" hydrogen cations (Artiolli et al., 2010).

In the last two decades, $\beta$-alanine has emerged as one of the most popular exerciserelated nutrients. Although relatively new to the scientific literature (the earliest scientific data on human use as an ergogenic aid were published in 2006), the number of formulations for increasing athletic performance containing $\beta$-alanine or a combination of other substances with $\beta$-alanine is particularly high. B-alanine is the precursor regulator of carnosine synthesis. B-alanine is an amino acid that, when combined with the amino acid histidine, forms the carnosine dipeptide in skeletal muscle. The consumption of 4-6 gr/day $\beta$-alanine has been shown to increase muscle carnosine concentration by up to $64 \%$ after 4 weeks, and more than 80\% after 10 weeks (Baquet et al., 2009). Maximum levels of muscle carnosine have not yet been determined. Higher carnosine levels have been reported in resistance muscle and sprinters, while $\beta$-alanine appears to increase muscle carnosine in trained and untrained people (Trexler et al., 2015).

The majority of the studies that have assessed increases in muscle carnosine have been performed in young men, but there is credible evidence that $\beta$-alanine is effective in both women and the elderly (Baquet et al., 2012). The increase in total muscle carnosine concentration may be slightly higher in trained athletes compared to non-athletes after $\beta$ alanine administration (Bex et al., 2014).

The ergogenic action of carnosine appears to be due to its ability to play the role of a muscle $\mathrm{pH}$ regulator. Anaerobic glycolysis produces lactic acid, which in turn breaks down into lactic ions and $\mathrm{H}^{+}$. Carnosine has the property of binding $\mathrm{H}^{+}$thus preventing the decrease of $\mathrm{pH}$ in the muscle cell. It also helps release $\mathrm{Ca}^{++}$, which plays an important role in muscle contraction (Trexler et al., 2015). Carnosine is found in both muscle types in the body, but in higher concentrations is found in type II muscle fibers, which are more related to the exercise of maximum strength and intensity (Baquet et al., 2009). Carnosine blocks the $\mathrm{H}^{+}$produced, thus increasing the ability to produce lactic acid without adversely affecting the muscle cell.

Research has shown that reactive oxygen by-products (ROS), which are produced at an increased rate during exercise, can cause muscle damage and stiffness (Klebanov et al., 1998). Carnosine appears to act as an antioxidant by neutralizing free radicals and lone oxygen (ROS), thus reducing oxidative stress (Bailey, Davies, Young, Hullin \& Seddon, 2001; Kohen R, Yamamoto Y, Cundy KC \& Ames,1998). Carnosine can also reduce oxidative stress by binding circulating metals such as copper and iron, thus preventing them from reacting with peroxides, leading to the production of free radicals (Decker, Crum \& Calvert, 1992).

Overall, how does carnosine work? Exercise and in particular the process of anaerobic glycolysis releases a lot of $\mathrm{H}^{+}$which reduces the muscle $\mathrm{pH}$, consequently, due to the large drop in $\mathrm{pH}$ the athletic performance decreases. Carnosine "intervenes" and neutralizes a significant number of $\mathrm{H}^{+}$, thus stabilizing the $\mathrm{pH}$ at concentrations that do 
not cause metabolic acidification and high-intensity exercise can be continued, so athletic performance is improved due to the delay of fatigue (Boldyrev, Aldini \& Derave, 2013).

More specifically, carnosine:

1) Contributes to the regulatory capacity of $\mathrm{H}^{+}$(protons).

2) Acts as a regulator of calcium release (calcium, $\mathrm{Ca}$ ) and calcium sensitivity

3) Protects reactive oxygen species (ROS)

4) Binds the transition of metal ions and

5) Supplies extracellular histidine and histamine (Trexler et al., 2015).

The high concentrations of carnosine in muscle and its $\mathrm{pH}$ (6.83) make it more effective in removing $\mathrm{H}^{+}$from muscle compared to either bicarbonate $(\mathrm{pH}=6.3)$ or inorganic phosphate $(\mathrm{pH}=7.2)$. The chemical structure of carnosine enables it to precede bicarbonate in the process of accepting $\mathrm{H}^{+}$produced during exercise. Although animal studies have shown that carnosine contributes to the removal of $\mathrm{H}^{+}$from muscle by $40 \%$, human studies have shown that the contribution is very low $(7 \%)$. In conclusion, $\beta$-alanine administration alleviates exercise-induced $\mathrm{pH}$ reduction (Saunders, McNaughton \& Siegler, 2021). The role of carnosine as an intracellular regulator of $\mathrm{H}^{+}$was first documented by Severin et al., (1953), who demonstrated that the absence of carnosine resulted in faster fatigue and acidification. More evidence of the carnosine contribution to the muscle is needed to further determine its role in athletic performance.

\subsection{Effect of $\beta$-alanine on Athletic Performance}

Given that $\beta$-alanine, as seen above, is the precursor regulator of carnosine production, it has been shown that its administration consistently increases the concentration of carnosine in various populations, and therefore may improve performance during highintensity exercise and/or improve the quality of athletic training involved in strength and power sports.

\subsubsection{B-alanine and Anaerobic Exercise}

Meta-analysis showed that $\beta$-alanine administration improved the ability to exercise in activities lasting 60-240 sec, but not in activities ( $<60 \mathrm{sec}$ ) in which acidification is not likely to be the main limiting factor (Hobson, Saunders, Ball, Harris \& Sale, 2012). In addition, literature data that repeatedly evaluated short sprints $(5-60 \mathrm{sec})$ do not appear to have a positive effect (Suzuki, Ito, Mukai, Takahashi \& Takamatsu, 2002; Sweeney, Wright, Glenn Brice \& Doberstein, 2010). Other findings found a positive effect of its administration on athletes' exhausted time (TTE) in activities (roads, cycling) less than 270 sec (Hill et al., 2007; Baquet et al., 2010; Chung et al., 2012; Ducker et al., 2013). Also, research has shown that $b$-alanine administration significantly improved the performance of women who ran at $90 \%$ and $100 \%$ of their speed, until exhaustion (average duration of effort=267.6 and $132.3 \mathrm{sec}$ ) (Smith-Ryan, Fukuda, Stout \& Kendall, 2012). However, not all scientific findings fully agree that there is a positive effect on tests lasting 1-4 min.

A recent meta-analysis concluded that $\beta$-alanine administration significantly improved the ability to practice in distance tests (e.g. $800 \mathrm{~m}$ road, $2,000 \mathrm{~m}$ rowing, etc.). The 
highest relative effect (improvement) was observed in trials lasting 63-141 sec (Huerta et al., 2020).

In conclusion, $\beta$-alanine improves high-intensity exercise lasting more than $60 \mathrm{sec}$, with greater effects on exercise at repetitive intervals, such as time to exhaustion. Overall, research today shows that $\beta$-alanine has the greatest potential for improving performance in high-intensity exercise lasting more than $60 \mathrm{sec}$ and specifically for 60-240 sec.

\subsubsection{B-alanine and Aerobic Exercise}

The results regarding the effect of $\beta$-alanine administration on aerobic exercise are conflicting. For exercise periods longer than $4 \mathrm{~min}$, the ATP requirement is met primarily through the aerobic energy pathway (ACSM, 2006). As such, $\beta$-alanine is not beneficial for exercise periods $>4 \mathrm{~min}$. On the contrary, a meta-analysis concluded that its administration resulted in improvements in trials $>4 \mathrm{~min}$, compared with placebo, although the magnitude of the effect was smaller compared to that of activities lasting 14 min (Huerta et al., 2020). Also, in studies in which the time to exhaustion and exercise lasted 20 min was measured, a slight improvement of 2-3\% in performance was recorded due to its administration (Sale, Hill, Ponte \& Harris, 2012; Huerta et al., 2020).

Benefits have also been reported in activities at a specific distance, lasting $>4 \mathrm{~min}$ (Van Thienen et al., 2009). For example, studies have reported that the time at 2,000 m rowing improved from 2.9-4.3 sec in participants receiving $\beta$-alanine relative to placebo (Baguet, Bourgois, Vanhee, Achten \& Derave, 2010). Until recently, few data were available for exercise lasting $>25 \mathrm{~min}$. In studies where the exercise lasted from 50-60 min, no significant improvement due to placebo was reported compared to placebo groups (Sale, Saunders \& Harris, 2010; Smith-Ryan et al., 2014). Overall, $\beta$-alanine administration may bring about a modest improvement in exercise lasting up to $25 \mathrm{~min}$, but beyond this time limit, to date, there are no consistent positive findings.

In conclusion, $\beta$-alanine can improve the duration of exercise in activities that require a greater contribution from the aerobic energy pathway.

\subsubsection{B-alanine and Strength}

Studies examining the effect of $\beta$-alanine on strength reported mixed findings. In studies administered $\beta$-alanine for $\sim 30$ days no significant improvements in strength parameters were found (Tallon, Harris, Boobis, Fallowfield \& Wise, 2005). Similarly, 8 weeks of administration did not improve strength in wrestlers and soccer players compared to placebo groups (Kendrick et al., 2009). In contrast, a study by Sale et al., (2013) found a significant improvement due to administration in isometric strength and muscle endurance after 4 weeks. It has been hypothesized that documented improvements in training volume and fatigue can be attributed to the administration of the substance in prolonged interventions (Tobias et al., 2013). A study that investigated the effect of creatine and creatine $+\beta$-alanine in combination with 10 weeks of resistance training showed that both groups compared to placebo significantly improved maximum strength and training volume (Kendrick et al., 2008). Collectively, the findings suggest that $\beta$ alanine may improve parameters related to workout volume and fatigue in resistance 
training. More and longer studies are needed to clarify possible positive effects on strength.

In conclusion, $\beta$-alanine appears to increase the volume of training; however, current research does not suggest an additional benefit for increasing strength during resistance training.

\subsubsection{B-alanine and Neuromuscular Fatigue}

A study showed that after 28 days of $\beta$-alanine administration, there was an improvement in the neuromuscular threshold of fatigue of $23 \%$ in female cyclists (Glenn et al., 2015). Another study revealed among female that 4 weeks of b-alanine supplementation delays the onset of neuromuscular fatigue and the ventilatory threshold at submaximal workloads, and increase in time to exhaustion during maximal cycle ergometry performance (Stout et al., 2007). Six weeks of intermittent training with concomitant administration of $\beta$-alanine, improved by $20.4 \%$ the electromyographic fatigue threshold in physically active individuals (Smith et al., 2009). In a sample of older participants (70.7 \pm 6.2 years), administration of $1200 \mathrm{mg} \beta$-alanine for 12 weeks improved the neuromuscular fatigue threshold compared with the placebo group, while, in a similar study in the elderly (72.8 \pm 11.1 years), 90 days of $\beta$-alanine administration improved the fatigue threshold by $37.3 \%$ (Trexler et al., 2015). B-alanine administration alleviates neuromuscular fatigue in repeated bouts of exhaustive dynamic contractions (Derave et al., 2007; Hoffman et al., 2008). Improvements in the neuromuscular fatigue threshold can be enhanced by participating in high-intensity interval training.

In conclusion, $b$-alanine supplementation seems to improve perceived exertion and biochemical parameters related to muscle fatigue (Berti Zanella, Donner Alves \& Guerini de Souza, 2017), while the effect of $\beta$-alanine on neuromuscular fatigue appears to be more pronounced in longer-duration studies in which older individuals were used.

\subsubsection{B-alanine and Tactical Activities Athletes}

Initial results in tactical athletes show a positive effect of $\beta$-alanine administration mainly in specialized military tactical activities. Soldiers who participated in military training with concomitant administration of $\beta$-alanine for 28 days appeared to have an improvement in shooting and targeting speed compared to the placebo group (Hoffman et al., 2014). Another study by the same group in soldiers showed that $\beta$-alanine significantly increased muscle carnosine, cognitive function, and performance in a $50 \mathrm{~m}$ injured transport simulation test (Hoffman et al., 2015). The training and duties of military personnel and other regular athletes often consisted of prolonged and strenuous exercise, resulting in reductions in physical and cognitive performance. B-alanine administration may bring benefits to this population, such as possibly reducing fatigue, enhancing neuromuscular performance, and reducing oxidative stress.

Recently, it has been reported that alanine administration has no significant effect on carnosine levels in the brain or on cognitive function in non-regular sports (Trexler et al., 2015). Although insufficient data are available, beta-alanine administration appears to 
yield promising results for regular activity. More research is needed to determine exactly which activities consistently improve after substance administration.

\subsection{B-alanine and Health}

Research supports a potentially positive role for carnosine in influencing certain healthrelated mechanisms, including its antioxidant properties, anti-aging, immune-boosting, and neurotransmitter actions (Gariballa \& Sinclair, 2000). However, most of these health benefits have been explored in vitro and animal models. Carnosine is widely regarded as an important anti-glycosylation agent that serves to prevent reactions that threaten to affect the structure and function of proteins in the body. The end products of glycosylation are associated with the aging process and diabetic complications, but carnosine is believed to reduce the formation of these end products (Hipkiss, Brownson \& Carrier MJ, 2001). Previous research has also shown that carnosine acts as a "sacrificial peptide" by reacting with carbonyl groups on aldehydes, ketones, and proteins to prevent protein damage (Hipkiss, Cartwright, Bromley, Gross, Bill, 2013). Carnosine is also known to be an antioxidant that is capable of preventing the accumulation of oxidized products derived from lipid components of biological membranes (Decker, Ivanov, Zhu \& Frei, 2001).

The antioxidant activity of carnosine especially in athletes has been adequately investigated (Trexler et al., 2015). Concentrations such as those recommended have a synergistic antioxidant effect. Research suggests that $\beta$-alanine may effectively reduce lipid peroxidation and mitigate the accumulation of free radicals when combined with aerobic exercise in men and women (Hipkiss, Michaelis \& Syrris, 1995). Sufficient future research is needed to evaluate the possible anti-aging effect and the impact of the possible antioxidant properties of the substance, especially after the positive results that have been recorded in older people (Hipkiss AR, 2005; (Hoffman, Emerson \& Stout, 2012).

In conclusion, $\beta$-alanine may act as an antioxidant.

\subsection{B-alanine in Combination with Other Supplements}

\subsubsection{Combination of $\beta$-alanine with Sodium Bicarbonate}

The combined effects of $\beta$-alanine with other ergogenic aids, such as sodium bicarbonate, creatine, and multi-ingredient formulas, have gained much publicity in recent years. Due to the possible positive effects of $\beta$-alanine during high-intensity exercise, it has been hypothesized that its combination with other ergogenic aids may further increase athletic performance and $\mathrm{H}^{+}$removal. Research examining the combination of substances in athletic performance showed that $\beta$-alanine improved performance in a cycling test to $110 \%$ of maximum strength and that there was a $70 \%$ chance of an additional effect by combining $\beta$-alanine and sodium bicarbonate (Sale et al., 2011). Another study that examined the effect of $\beta$-alanine, sodium bicarbonate, and their combination showed that the substances alone improved the maximum strength of the practitioners but their combination did not bring significantly better results than the substances alone (Ducker, Dawson \& Wallman, 2013) ${ }^{\mathrm{a}}$. In the $2,000 \mathrm{~m}$ rowing race, the researchers concluded that $\beta$ alanine was very likely to improve timing performance $(96 \%$ probability of positive effect), that sodium bicarbonate was likely to improve performance (87\% probability) 
(Hobson et al., 2013). Moreover, there was an additional effect when combining chronic b-alanine supplementation with acute sodium bicarbonate supplementation as compared to chronic b-alanine supplementation alone (Hobson et al., 2013). Studies in $100 \mathrm{~m} \& 200$ $\mathrm{m}$ swimmers have shown that the combination of $\beta$-alanine and sodium bicarbonate had a $71.8 \%$ and $78.5 \%$ probability, respectively, of an additional positive effect (Painelli et al., 2013). In contrast, studies in $2 \times 100 \mathrm{~m}$ swimming, $3 \times 6 \times 20 \mathrm{~m}$ sprint \& $5 \times 6$ sec did not show a synergistic effect between $\beta$-alanine and sodium bicarbonate (Mero et al., 2013). In summary, it appears that when sodium bicarbonate is added to $\beta$-alanine, a moderate additional effect occurs in sports in which metabolic oxidation is likely to limit performance. The above studies have used 4.8-6.8 gr $/ \mathrm{kg} /$ day of $\beta$-alanine for at least 28 days, and 0.3-0.5 $\mathrm{gr} / \mathrm{kg}$ of sodium bicarbonate given once.

\subsubsection{Combination of $\beta$-alanine with Creatine}

Studies in cyclists and soccer players have shown that the combination of $\beta$-alanine and creatine further improved strength and power, respectively, compared to creatine alone (studies did not include the comparison with $\beta$-alanine) (Hoffman, Emerson \& Stout, 2012). A study by Stout et al., (2006) showed that $\beta$-alanine and the combination of $\beta$ alanine and creatine improved maximal potency compared to creatine and placebo, but not compared to $\beta$-alanine alone. Another study by Kresta et al., (2014) that investigated aerobic and anaerobic exercise parameters and included groups that consumed $\beta$-alanine, creatine and their combination reported that no synergistic effect of the two substances was found.

Although some studies show a synergistic effect of the two substances, more research is needed to draw firm conclusions. Overall, the literature suggests that transient or chronic substance use may improve athletic performance and body composition. However, especially in the case of commercial formulations, it is difficult to attribute this ergogenic effect to $\beta$-alanine alone, as most contain several ergogenic substances that can improve performance independently (e.g., caffeine, creatine). Given the regulatory capacity of carnosine in muscle $\mathrm{H}^{+}, \beta$-alanine appears to improve performance in highintensity exercise that can cause intramuscular acidosis. Creatine supplements have been consistently shown to improve performance in high-intensity exercise, mainly through increased phosphocreatine and adenosine triphosphate (ATP) availability (Harris, Hill \& Wise, 2003; Hoffman, Emerson \& Stout, 2012).

In conclusion, co-ingestion of $\beta$-alanine with sodium bicarbonate or creatine has modest additional ergogenic benefits. Ingestion of $\beta$-alanine as part of a multi-ingredient product before training may be effective if the administration period is sufficient to increase carnosine levels and the product is taken for at least 4 weeks.

\subsection{Administration Protocols}

B-Alanine is provided in solution or powder. A charging phase ( $\sim$ weeks) of $\beta$-alanine is necessary to increase carnosine levels. Beta-alanine administration usually takes several weeks (at least 2 weeks) to yield significant increases in muscle carnosine content. Therefore, $\beta$-alanine is unlikely to improve athletic performance in studies in which the 
supplement is used in the acute phase and as a single dose (Stegen et al., 2014). In studies lasting 4 to 8 weeks, $\beta$-alanine is more likely to help improve performance and indirectly in body composition. Although it is difficult to determine the relative contributions of the individual components, research has shown that many pre-workout multi-supplement components containing 2-4 gr of $\beta$-alanine are safe and effective when taken acutely, or chronically for up to 8 weeks.

The $\beta$-alanine delivery strategy is important to maximize its effect. It is suggested that $\beta$-alanine requires a chronic loading dose of 4-6 gr/day in subunits of 2 gr or less for a minimum of 2 weeks (resulting in a 20-30\% increase in muscle carnosine), with a higher benefit occurring after 4 weeks (40-60\% increase) (Stellingwerff, Decombaz, Harris \& Boesch, 2012). To increase muscle carnosine, a higher dose of 6 gr (e.g. 6.8), divided into 4 equal portions may be more beneficial. Single high doses of $\beta$-alanine have been shown to cause paraesthesia (e.g., numbness), and may not be effective in athletic performance due to strong paraesthesia, rapid $\mathrm{pH}$ changes, higher excretion rates, and an inability to "effectively" load the muscles with carnosine (Stellingwerff et al., 2012). Combining the consumption of $\beta$-alanine with a carbohydrate meal during the loading period, due to the increase in insulin created thus accelerating absorption by muscle cells, is effective in further increasing muscle carnosine levels. Also, a recent meta-analysis (Hobson et al., 2012) suggests that a total intake of 179 gr of $\beta$-alanine (the average intake in all studies) resulted in an average yield improvement of $2.85 \%$ compared to placebo. The time it takes for muscle carnosine values to return to normal varies from person to person and ranges from 6-15 weeks. The above is not the optimal dose for charging or maintaining muscle carnosine (Trexler et al., 2015).

\subsection{Safety and Side Effects}

It seems to be safe to administer in healthy populations and at the recommended doses. The only side effect reported is paraesthesia (tingling) when taken in doses above 10 $\mathrm{mg} / \mathrm{kg}$ body weight (TW) and this varies between different individuals. In some people the symptoms are felt from $10 \mathrm{mg} / \mathrm{kg} \mathrm{BW}$, in the majority, they are felt from $20 \mathrm{mg} / \mathrm{kg} \mathrm{BW}$, while others need a concentration of $40 \mathrm{mg} / \mathrm{kg}$ to begin to feel the symptoms of an overdose (Trexler et al., 2015).

A study by Harris et al., (2013) indicated that this symptom can be alleviated by using lower doses (e.g., 4 doses of $1.5 \mathrm{gr}$ ) or by using prolonged-release capsules. However, injectable doses of $40 \mathrm{mg} / \mathrm{kg}$ body weight $\beta$-alanine, but in L-histidine dipeptides in chickens did not cause paraesthesia. A possible side effect of $\beta$-alanine administration is a reduction in taurine concentration. B-Alanine and taurine share the same transporter (Tau-T) in skeletal muscle, and therefore $\beta$-alanine potentially inhibits taurine uptake into muscle. Research (Harris et al., 2000) showed that 4 weeks of $\beta$-alanine administration (10-40 mg/kg body weight) increased plasma taurine concentration; however, there was no significant decrease in taurine concentration. Given that taurine is involved in essential physiological functions, to date, there is insufficient evidence in humans to support its reduction due to $\beta$-alanine administration. 


\subsection{Recommendations}

- Administration for 4 weeks (4-6 gr/day) significantly increases muscle carnosine stores, acting as an intramuscular system for regulating $\mathrm{H}^{+}$concentration.

- Requires a chronic loading dose of 4-6 gr/day in doses of 2 gr or less, for a minimum of 2 weeks, while a higher benefit occurs after 4 weeks.

- Improves performance in anaerobic exercise, with a more pronounced effect in trials lasting 1 to $4 \mathrm{~min}(60-240 \mathrm{sec})$ and high intensity.

- Does not seem to help at all in less than 60 seconds.

- It also seems that its ergogenic action is small to moderate in exercise lasting up to $25 \mathrm{~min}$, but above this limit, there are no consistent positive findings.

- Relieves neuromuscular fatigue, especially in the elderly and new data indicate that it can also improve performance in tactic activities athletes.

- Increases the volume of resistance training, however, there is no additional benefit to increasing strength.

- Co-ingestion of $\beta$-alanine with sodium bicarbonate or creatine has moderate additional ergogenic benefits.

- In soleus muscles, the efficiency of carnosine loading is significantly higher when b-alanine is coingested with a meal compared with in between the meals (Stegen et al., 2013)

- B-Alanine may act as an antioxidant.

- It is safe to administer at the recommended doses and the only side effect is paraesthesia (tingling) (Trexler et al., 2015; Huerta Ojeda et al., 2020). This section contains theoretical and practical recommendations, further research ideas, approaches, suggestions, and concerns regarding potential social and cultural impacts, etc.

\section{Conclusions}

Sodium bicarbonate and b-alanine are legal ergogenic aid, cheap, and easy to produce and they have been administrated to athletes for the last decades. Consumption of sodium bicarbonate can increase the concentrations of bicarbonate in the blood, enhancing the extracellular mechanism of "neutralization" of hydrogen ions that accumulate in the exercised muscle. The optimal dose ranges from 0.3 to $0.5 \mathrm{gr} / \mathrm{kg}$ body weight and to avoid or reduce gastrointestinal disorders it is recommended to consume 150-180 min before exercise. The effect of sodium bicarbonate on athletic performance also depends on its judicious use, i.e. on the application of such a dosing protocol so as not to cause adverse symptoms, especially in competitions with repeated races (e.g. qualifiers, semi-finals, finals). Consumption of b-alanine also can enhance athletic performance in anaerobic exercise, with a more pronounced effect in trials lasting 1 to $4 \mathrm{~min}(60-240 \mathrm{sec})$ and high intensity, while it also seems that its ergogenic action is small to moderate in exercise lasting up to $25 \mathrm{~min}$. Moreover, it increases the volume of resistance training; however, there is no additional benefit to increasing strength. Administration for 4 weeks (4-6 gr/day) significantly increases muscle carnosine stores, acting as an intramuscular system 
for regulating $\mathrm{H}^{+}$concentration. Additionally, it is required a loading dose of 4-6 gr/day in doses of 2 gr or less, for a minimum of 2 weeks, while, a higher benefit occurs after 4 weeks. The only side effect at the recommended doses is paraesthesia (tingling).

\title{
Acknowledgements
}

This work was supported by the Graduate Program, Department of Nutrition and Dietetics of Harokopio University, Greece.

\section{Conflict of Interest Statement}

The authors declare no conflicts of interest.

\begin{abstract}
About the Authors
Konstantinos D. Tambalis, (MSc, MSc, PhD) is a Teaching and Research Associate at the Department of Nutrition and Dietetics of the Harokopio University in Greece. His research interests are in the areas of Physical Education, epidemiology of exercise and athletic nutrition.

Giannis Arnaoutis, (MSc, PhD) is a Teaching and Research Associate at the Department of Nutrition and Dietetics of the Harokopio University in Greece. His research interests are in the areas of athletic nutrition, exercise physiology and exercise performance.
\end{abstract}

\section{References}

American College of Sports Medicine, 2006. Advanced Exercise Physiology. Lippinkott Williams \& Wilkins. Philadelphia, USA.

Artioli GG, Gualano B, Smith A, Stout J, Lancha AH, 2010. Role of b-alanine supplementation on muscle carnosine and exercise performance. Medicine and Science in Sports and Exercise 42: 1162-1173. https://doi.org/10.1249/MSS.0b013e3181c74e38.

Bailey DM, Davies B, Young IS, Hullin DA, Seddon PS, 2001. A potential role for free radical-mediated skeletal muscle soreness in the pathophysiology of acute mountain sickness. Aviation, Space and Environmental Medicine 72(6): 513521.PMID: 11396556.

Baguet A, Reyngoudt H, Pottier A, Everaert I, Callens S, Achten E, Derave W, 2009. Carnosine loading and washout in human skeletal muscles. Journal of Applied Physiology 106(3): 837-842. https://doi.org/10.1152/japplphysiol.91357.2008.

Baguet A, Bourgois J, Vanhee L, Achten E, Derave W, 2010. Important role of muscle carnosine in rowing performance. Journal of Applied Physiology 109: 1096-1101. https://doi.org/10.1152/japplphysiol.00141.2010.

Baguet A, Koppo K, Pottier A, Derave W, 2010. Beta-alanine supplementation reduces acidosis but not oxygen uptake response during high-intensity cycling exercise. European Journal of Applied Physiology 108: 495-503. https://doi.org/10.1007/s00421-009-1225-0. 
Baguet A, Everaert I, Achten E, Thomis M, Derave W, 2012. The influence of sex, age and heritability on human skeletal muscle carnosine content. AminoAcids43: 13-20. https://doi.org/10.1007/s00726-011-1197-3.

Berti Zanella P, Donner Alves F, Guerini de Souza C, 2017. Effects of beta-alanine supplementation on performance and muscle fatigue in athletes and non-athletes of different sports: a systematic review. The Journal of Sports Medicine and Physical Fitness 57(9): 1132-1141. https://doi.org/10.23736/S0022-4707.16.06582-8.

Bex T, Chung W, Baguet A, Stegen S, Stautemas J, Achten E, Derave W, 2014. Muscle carnosine loading by beta-alanine supplementation is more pronounced in trained vs. untrained muscles. Journal of Applied Physiology 116(2): 204-209. https://doi.org/10.1152/japplphysiol.01033.2013.

Boldyrev AA, Aldini G, Derave W, 2013. Physiology and pathophysiology of carnosine. Physiology Reviews 93(4): 1803-1845. https://doi.org/10.1152/physrev.00039.2012.

Brody T, 1999. Nutritional Biochemistry, $2^{\text {nd }}$ edn. California, USA.

Burke LM, 2013. Practical considerations for bicarbonate loading and sports performance. Nestle Nutrition Institute Workshop Series 75: 15-26. https://doi.org/10.1159/000345814.

Burke L, Deakin V, 2006. Clinical Sports Nutrition, $3^{\text {rd }}$ edn. Sydney, Australia.

Cameron SL, McLay-Cooke RT, Brown RC, Gray AR, Fairbairn KA, 2010. Increased blood $\mathrm{pH}$ but not performance with sodium bicarbonate supplementation in elite rugby union players. International Journal of Sport Nutrition and Exercise Metabolism, 20(4), 307-321. https://doi.org/10.1123/ijsnem.20.4.307.

Caspersen, CJ, Powell KE, Christenson GM, 1985. Physical activity, exercise, and physical fitness: definitions and distinctions for health-related research. Public Health Reports 100: 126-131.PMID: 3920711.

Carr AJ, Hopkins WG, Gore CJ, 2011. Effects of acute alkalosis and acidosis on performance: a meta-analysis. Sports Medicine 41(10): 801-814. https://doi.org/10.2165/11591440-000000000-00000.

Carr AJ, Gore CJ, Dawson B, 2011. Induced alkalosis and caffeine supplementation: effects on 2,000-m rowing performance. International Journal of Sport Nutrition and Exercise Metabolism 21(5): 357-364. https://doi.org/10.1123/ijsnem.21.5.357.

Carr AJ, Slater GJ, Gore CJ, Dawson B, Burke LM, 2011. Effect of sodium bicarbonate on [HCO3-], pH, and gastrointestinal symptoms. International Journal of Sport Nutrition and Exercise Metabolism 21(3): 189-194. https://doi.org/10.1123/ijsnem.21.3.189.

Carr AJ, Slater GJ, Gore CJ, Dawson B, Burke LM, 2012. Reliability and effect of sodium bicarbonate: buffering and 2000-m rowing performance. International Journal of $\begin{array}{lllll}\text { Sports } & \text { Physiology } & \text { 152-160. }\end{array}$ https://doi.org/10.1123/ijspp.7.2.152.

Carr BM, Webster MJ, Boyd JC, Hudson GM, Scheett TP, 2013. Sodium bicarbonate supplementation improves hypertrophy-type resistance exercise performance. European Journal of Applied Physiology 113(3): 743-752. https://doi.org/10.1007/s00421-012-2484-8. 
Chung W, Shaw G, Anderson ME, Pyne DB, Saunders PU, Bishop DJ, Burke L, 2012. Effect of 10 week beta-alanine supplementation on competition and training performance in elite swimmers. Nutrients 4(10): 1441-1453. https://doi.org/10.3390/nu4101441.

Decker EA, Crum AD, Calvert JT, 1992. Differences in the antioxidant mechanism of carnosine in the presence of copper and iron. Journal of Agricultural and Food Chemistry 40(5): 756-759. https://doi.org/10.1021/jf00017a009.

Decker EA, Ivanov V, Zhu BZ, Frei B, 2001. Inhibition of low-density lipoprotein oxidation by carnosine histidine. Journal of Agricultural and Food Chemistry 49(1): 511-516. https://doi.org/10.1021/jf0010533.

Derave W, Ozdemir MS, Harris RC, Pottier A, Reyngoudt H, Koppo K, Wise JA, Achten E, 2007. beta-Alanine supplementation augments muscle carnosine content and attenuates fatigue during repeated isokinetic contraction bouts in trained sprinters. Journal of Applied Physiology 103(5): 1736-1743. https://doi.org/10.1152/japplphysiol.00397.2007.

Ducker KJ, Dawson B, Wallman KE, 2013. Effect of beta-alanine supplementation on 800$\mathrm{m}$ running performance. International Journal of Sport Nutrition and Exercise Metabolism 23(6): 554-561. https://doi.org/10.1123/ijsnem.23.6.554.

Ducker KJ, Dawson B, Wallman KE, 2013. Effect of Beta alanine and sodium bicarbonate supplementation on repeated-sprint performance. Journal of Strength and Conditioning 27(12): $\quad$ Research 3450-3460. https://doi.org/10.1519/JSC.0b013e31828fd310.

Ducker KJ, Dawson B, Wallman KE, 2013. Effect of beta-alanine supplementation on 2000$\mathrm{m}$ rowing-ergometer performance. International Journal of Sport Nutrition and Exercise Metabolism 23(4): 336-343. https://doi.org/10.1123/ijsnem.23.4.336.

Edge J, Bishop D, Goodman C, 2006. Effects of chronic NaHCO3 ingestion during interval training on changes to muscle buffer capacity, metabolism, and short-term endurance performance. Journal of Applied Physiology 101(3): 918-925. https://doi.org/10.1152/japplphysiol.01534.2005.

Driller MW, Gregory JR, Williams AD, Fell JW, 2013. The effects of chronic sodium bicarbonate ingestion and interval training in highly trained rowers. International Journal of Sport Nutrition and Exercise Metabolism 23(1): 40-47. https://doi.org/10.1123/ijsnem.23.1.40.

Joyce S, Minahan C, Anderson M, Osborne M, 2012. Acute and chronic loading of sodium bicarbonate in highly trained swimmers. European Journal of Applied Physiology 112(2): 461-469. https://doi.org/10.1007/s00421-011-1995-z.

Hoffman JR, Emerson NS, Stout JR, 2012. $\beta$-Alanine supplementation. Current Sports Medicine Reports 11(4): 189-195. https://doi.org/10.1249/ISR.0b013e3182604983.

Gariballa SE, Sinclair AJ, 2000. Carnosine: physiological properties and therapeutic potential. Age Ageing 29(3): 207-210.https://doi.org/10.1093/ageing/29.3.207.

Glenn JM, Gray M, Stewart R, Moyen NE, Kavouras SA, DiBrezzo R, Turner R, Baum J, 2015. Incremental effects of 28 days of beta-alanine supplementation on highintensity cycling performance and blood lactate in masters female cyclists. Amino Acids 47(12): 2593-2600. https://doi.org/10.1007/s00726-015-2050-x. 
Grgic J, Pedisic Z, Saunders B, Artioli GG, Schoenfeld BJ, McKenna MJ, et al., 2021. International Society of Sports Nutrition position stand: sodium bicarbonate and exercise performance. Journal of the International Society of Sports Nutrition 18(1): 61. https://doi.org/10.1186/s12970-021-00458-w.

Harris RC, Hill C, Wise JA, 2003. Effect of combined beta-alanine and creatine monohydrate supplementation on exercise performance (Abstract). Medicine and Science in Sports and Exercise 35(5): S218.

Harris RC, Stellingwerff T, 2013. Effect of $\beta$-alanine supplementation on high-intensity exercise performance. Nestle Nutrition Institute workshop series 76: 61-71. https://doi.org/10.1159/000350258.

Hill CA, Harris RC, Kim HJ, Harris BD, Sale C, Boobis LH, Kim CK, Wise JA, 2007. Influence of beta-alanine supplementation on skeletal muscle carnosine concentrations and high intensity cycling capacity. AminoAcids 32(2): 225-233. https://doi.org/10.1007/s00726-006-0364-4.

Hipkiss AR, Michaelis J, Syrris P, 1995. Non-enzymatic glycosylation of the dipeptide Lcarnosine, a potential anti-protein-cross-linking agent. FEBS Letters 371(1): 81-85. https://doi.org/10.1016/0014-5793(95)00849-5.

Hipkiss AR, Brownson C, Carrier MJ, 2001. Carnosine, the anti-ageing, anti-oxidant dipeptide, may react with protein carbonyl groups. Mechanisms of Ageing and Development 122(13): 1431-1445. https://doi.org/10.1016/s0047-6374(01)00272-x.

Hipkiss AR, 2005. Glycation, ageing and carnosine: are carnivorous diets beneficial? Mechanisms of Ageing and Development 126(10): 1034-1039. https://doi.org/10.1016/j.mad.2005.05.002.

Hipkiss AR, Cartwright SP, Bromley C, Gross SR, Bill RM, 2013. Carnosine: can understanding its actions on energy metabolism and protein homeostasis inform its therapeutic potential? Chemistry Central Journal 7(1): 38. https://doi.org/10.1186/1752-153X-7-38.

Hobson RM, Saunders B, Ball G, Harris RC, Sale C, 2012. Effects of beta-alanine supplementation on exercise performance: a meta-analysis. Amino Acids 43(1):2537. https://doi.org/10.1007/s00726-011-1200-z.

Hobson RM, Harris RC, Martin D, Smith P, Macklin B, Gualano B, Sale C, 2013. Effect of Beta-Alanine with and Without Sodium Bicarbonate on 2,000-m Rowing Performance. International Journal of Sport Nutrition and Exercise Metabolism 23(5): 480-487. https://doi.org/10.1123/ijsnem.23.5.480.

Hoffman JR, Ratamess NA, Faigenbaum AD, Ross R, Kang J, Stout JR, Wise J, 2008. Shortduration beta-alanine supplementation increases training volume and reduces subjective feelings of fatigue in college football players. Nutrition Research 28(1): 31-35. https://doi.org/10.1016/j.nutres.2007.11.004.

Hoffman JR, Landau G, Stout JR, Dabora M, Moran DS, Sharvit N, et al., 2014. beta-alanine supplementation improves tactical performance but not cognitive function in combat soldiers. Journal of the International Society of Sports Nutrition 11(1): 15. https://doi.org/10.1186/1550-2783-11-15. 
Hoffman JR, Emerson NS, Stout JR, 2012. $\beta$-Alanine supplementation. Current Sports Medicine Reports 11(4): 189-195. https://doi.org/10.1249/JSR.0b013e3182604983.

Hoffman JR, Landau G, Stout JR, Hoffman MW, Shavit N, Rosen P, et al., 2015. betaAlanine ingestion increases muscle carnosine content and combat specific performance in soldiers. Amino Acids 47(3): 627-636. https://doi.org/10.1007/s00726-014-1896-7.

Hollidge-Horvat MG, Parolin ML, Wong D, Jones NL, Heigenhauser GJ, 2000. Effect of induced metabolic alkalosis on human skeletal muscle metabolism during exercise. American Journal of Physiology Endocrinology and Metabolism 278(2): E316-329. https://doi.org/10.1152/ajpendo.2000.278.2.E316.

Huerta Ojeda Á, Tapia Cerda C, Poblete Salvatierra MF, Barahona-Fuentes G, Jorquera Aguilera C, 2020. Effects of Beta-Alanine Supplementation on Physical Performance in Aerobic-Anaerobic Transition Zones: A Systematic Review and Meta-Analysis. Nutrients 12(9): 2490. https://doi.org/10.3390/nu12092490.

Katz A, Costill DL, King DS, Hargreaves M, Fink WJ, 1984. Maximal exercise tolerance after induced alkalosis. International Journal of Sports Medicine 5(2): 107-110. https://doi.org/10.1055/s-2008-1025890.

Kendrick IP, Harris RC, Kim HJ, Kim CK, Dang VH, Lam TQ, Bui TT, Smith M, Wise JA, 2008. The effects of 10 weeks of resistance training combined with beta-alanine supplementation on whole body strength, force production, muscular endurance and body composition. Amino Acids 34(4): 547-554. https://doi.org/10.1007/s00726-007-0008-3.

Kendrick IP, Kim HJ, Harris RC, Kim CK, Dang VH, Lam TQ, Bui TT, Wise JA, 2009. The effect of 4 weeks beta-alanine supplementation and isokinetic training on carnosine concentrations in type I and II human skeletal muscle fibres. European Journal of Applied Physiology 106(1): 131-138. https://doi.org/10.1007/s00421-009-0998-5.

Kilding AE, Overton C, Gleave J, 2012. Effects of caffeine, sodium bicarbonate, and their combined ingestion on high-intensity cycling performance. International Journal of Sport Nutrition and Exercise Metabolism 22(3): 175-183. https://doi.org/10.1123/ijsnem.22.3.175.

Klebanov GI, Teselkin Yu O, Babenkova IV, Lyubitsky OB, Rebrova O, Boldyrev AA, Vladimirov YA, 1998. Effect of carnosine and its components on free-radical reactions. Membrane \& Cell Biology 12(1): 89-99.PMID: 9829262.

Kohen R, Yamamoto Y, Cundy KC, Ames BN, 1988. Antioxidant activity of carnosine, homocarnosine, and anserine present in muscle and brain. Proceedings of the National Academy of Sciences of the United States of America 85(9): 3175-3179. https://doi.org/10.1073/pnas.85.9.3175.

Kreider RB, Wilborn CD, Taylor L, Campbell B, Almada AL, Collins R, et al., 2010. ISSN exercise \& sport nutrition review: research \& recommendations. Journal of International Society of Sports Nutrition 7: 7. https://doi.org/10.1186/1550-2783-7$\underline{7}$.

Kresta JY, Oliver JM, Jagim AR, Fluckey J, Riechman S, Kelly K, et al., 2014. Effects of 28 days of beta-alanine and creatine supplementation on muscle carnosine, body 
composition and exercise performance in recreationally active females. Journal of International Society of Sports Nutrition 11(1): 55. https://doi.org/10.1186/s12970014-0055-6.

Kupcis PD, Slater GJ, Pruscino CL, Kemp JG, 2012. Influence of sodium bicarbonate on performance and hydration in lightweight rowing. International Journal of Sports Physiology Performance 7(1): 11-18. https://doi.org/10.1123/ijspp.7.1.11.

Lancha J, Painelli V, Saunders B, Artioli GG, 2015. Nutritional Strategies to Modulate Intracellular and Extracellular Buffering Capacity During High-Intensity Exercise. Sports Medicine 45(Suppl 1): S71-81. https://doi.org/10.1007/s40279-015-0397-5.

Lindh AM, Peyrebrune MC, Ingham SA, Bailey DM, Folland JP, 2008. Sodium bicarbonate improves swimming performance. Interantional Journal of Sports Medicine 29(6): 519-523. https://doi.org/10.1055/s-2007-989228.

McNaughton LR, Gough L, Deb S, Bentley D, Sparks SA, 2016. Recent Developments in the Use of Sodium Bicarbonate as an Ergogenic Aid. Current Sports Medicine Reports 15(4): 233-244. https://doi.org/10.1249/JSR.0000000000000283.

Mero AA, Hirvonen P, Saarela J, Hulmi JJ, Hoffman JR, Stout JR, 2013. Effect of sodium bicarbonate and beta-alanine supplementation on maximal sprint swimming. Journal of International Society of Sports Nutrition 10(1): 52. https://doi.org/10.1186/1550-2783-10-52.

Painelli V, Roschel H, Jesus Fd, Sale C, Harris RC, Solis MY, Benatti FB, Gualano B, Lancha AH, Artioli GG, 2013. The ergogenic effect of beta-alanine combined with sodium bicarbonate on high-intensity swimming performance. Applied Physiology, Nutrition, and Mmetabolism 38(5): 525-532. https://doi.org/10.1139/apnm-2012$\underline{0286}$.

Peart DJ, Siegler JC, Vince RV, 2012. Practical recommendations for coaches and athletes: a meta-analysis of sodium bicarbonate use for athletic performance. Journal of Strength Conditioning Research 26(7): 1975-1983. Review. https://doi.org/10.1519/JSC.0b013e3182576f3d.

Price M, Moss P, Rance S, 2003. Effects of sodium bicarbonate ingestion on prolonged intermittent exercise. Medicine in Science and Sports Exercise 35(8): 1303-1308. https://doi.org/10.1249/01.MSS.0000079067.46555.3C.

Raymer GH, Marsh GD, Kowalchuk JM, Thompson RT, 1985. Metabolic effects of induced alkalosis during progressive forearm exercise to fatigue. Journal of Applied Physiology 96(6): 2050-2056. https://doi.org/10.1152/japplphysiol.01261.2003.

Sale C, Saunders B, Harris RC, 2010. Effect of beta-alanine supplementation on muscle carnosine concentrations and exercise performance. Amino Acids 39(2): 321-333. https://doi.org/10.1007/s00726-009-0443-4.

Sale C, Saunders B, Hudson S, Wise JA, Harris RC, Sunderland CD, 2011. Effect of $\beta$ alanine plus sodium bicarbonate on high-intensity cycling capacity. Medicine and Science in Sports and Exercise 43(10): 1972-1978. https://doi.org/10.1249/MSS.0b013e3182188501. 
Sale C, Hill CA, Ponte J, Harris RC, 2012. beta-alanine supplementation improves isometric endurance of the knee extensor muscles. Journal of the International Society of Sports Nutrition 9(1): 26. https://doi.org/10.1186/1550-2783-9-26.

Saunders B, McNaughton LR, Siegler J, 2021. Editorial: Nutritional Buffering Strategies to Improve Exercise Capacity and Performance. Frontiers in Nutrition 8: 669102. https://doi.org/10.3389/fnut.2021.669102.

Severin SE, Kirzon MV, Kaftanova TM, 1953. [Effect of carnosine and anserine on action of isolated frog muscles]. DoklAkadNauk SSSR 91(3): 691-694.PMID: 13095299.

Siegler JC, Gleadall-Siddall DO, 2010. Sodium bicarbonate ingestion and repeated swim sprint performance. Journal of Strength Conditioning Research 24(11): 3105-3111. https://doi.org/10.1519/JSC.0b013e3181f55eb1.

Siegler JC, Hirscher K, 2010. Sodium bicarbonate ingestion and boxing performance. Journal of Strength Conditioning Research 24(1): 103-108. https://doi.org/10.1519/JSC.0b013e3181a392b2.

Siegler JC, McNaughton LR, Midgley AW, Keatley S, Hillman A, 2010. Metabolic alkalosis, recovery and sprint performance. International Journal of Sports Medicine 31(11): 797-802. https://doi.org/10.1055/s-0030-1261943.

Siegler JC, Midgley AW, Polman RC, Lever R, 2010. Effects of various sodium bicarbonate loading protocols on the time-dependent extracellular buffering profile. Journal of Strength and Conditioning Research 24(9): 2551-2557. https://doi.org/10.1519/ISC.0b013e3181aeb154.

Smith AE, Moon JR, Kendall KL, Graef JL, Lockwood CM, Walter AA, et al., 2009. The effects of beta-alanine supplementation and high-intensity interval training on neuromuscular fatigue and muscle function. European Journal of Applied Physiology 105(3): 357-363. https://doi.org/10.1007/s00421-008-0911-7.

Smith-Ryan AE, Fukuda DH, Stout JR, Kendall KL, 2012. High-velocity intermittent running: effects of beta-alanine supplementation. Journal of Strength Conditioning Research 26(10): 2798-2805. https://doi.org/10.1519/ISC.0b013e318267922b.

Smith-Ryan AE, Woessner MN, Melvin MN, Wingfield HL, Hackney AC, 2014. The effects of beta-alanine supplementation on physical working capacity at heart rate threshold. Clinical Physiology and Functional Imaging 34(5): 397-404. https://doi.org/10.1111/cpf.12111.

Spriet LL, Perry CG, Talanian JL, 2008. Legal pre-event nutritional supplements to assist energy metabolism. Essays in Biochemistry 44: 27-43. Review. https://doi.org/10.1042/BSE0440027.

Stegen S, Bex T, Vervaet C, Vanhee L, Achten E, Derave W, 2014. beta-Alanine dose for maintaining moderately elevated muscle carnosine levels. Medicine and Science in $\begin{array}{llll}\text { Sports } \quad \text { and } & \text { Exercise } & \text { 1426-1432. }\end{array}$ https://doi.org/10.1249/MSS.0000000000000248.

Stegen S, Blancquaert L, Everaert I, Bex T, Taes Y, Calders P, Achten E, Derave W, 2013. Meal and beta-alanine coingestion enhances muscle carnosine loading. Medicine and Science in Sports and Exercise 45(8): 1478-1485. https://doi.org/10.1249/MSS.0b013e31828ab073. 
Stellingwerff T, Boit M, Res P, 2007. “Nutritional Strategies to Optimize Training and Racing in Middle-Distance Athletes. Journal of Sports Sciences 25: 17-28. https://doi.org/10.1080/02640410701607213.

Stellingwerff T, Anwander H, Egger A, Buehler T, Kreis R, Decombaz J, Boesch C, 2012. Effect of two $\beta$-alanine dosing protocols on muscle carnosine synthesis and washout. Amino Acids 42(6): 2461-2472. https://doi.org/10.1007/s00726-011-1054$\underline{4}$.

Stellingwerff T, Decombaz J, Harris RC, Boesch C, 2012. Optimizing human in vivo dosing and delivery of beta-alanine supplements for muscle carnosine synthesis. Amino Acids 43(1): 57-65. https://doi.org/10.1007/s00726-012-1245-7.

Stout JR, Cramer JT, Mielke M, O'Kroy J, Torok DJ, Zoeller RF, 2006. Effects of twentyeight days of beta-alanine and creatine monohydrate supplementation on the physical working capacity at neuromuscular fatigue threshold. Journal of Strength Conditioning Research 20: 928-931. https://doi.org/10.1519/R-19655.1.

Stout JR, Cramer JT, Zoeller RF, Torok D, Costa P, Hoffman JR, Harris RC, O'Kroy J, 2007. Effects of beta-alanine supplementation on the onset of neuromuscular fatigue and ventilatory threshold in women. Amino Acids 32(3): 381-386. https://doi.org/10.1007/s00726-006-0474-z.

Suzuki Y, Ito O, Mukai N, Takahashi H, Takamatsu K, 2002. High level of skeletal muscle carnosine contributes to the latter half of exercise performance during 30-s maximal cycle ergometer sprinting. The Japanese Journal of Physiology 52(2): 199_ 205. https://doi.org/10.2170/jiphysiol.52.199.

Sweeney KM, Wright GA, Glenn Brice A, Doberstein ST, 2010. The effect of beta-alanine supplementation on power performance during repeated sprint activity. Journal of Strength and Conditioning Research 24(1): 79-87. https://doi.org/10.1519/JSC.0b013e3181c63bd5.

Tallon MJ, Harris RC, Boobis LH, Fallowfield JL, Wise JA, 2005. The carnosine content of vastus lateralis is elevated in resistance-trained bodybuilders. Journal of Strength Conditioning Research 19(4): 725-729. https://doi.org/10.1519/041018.1.

Tambalis K, 2017. Nutritional support for athletes (Ergogenic Supplements), Athens, Greece.

Tan F, Polglaze T, Cox G, Dawson B, Mujika I, Clark S, 2010. Effects of induced alkalosis on simulated match performance in elite female water polo players. International Journalof Sport Nutrition and Exercise Metabolism 20(3): 198-205. https://doi.org/10.1123/ijsnem.20.3.198.

Tobias G, Benatti FB, de Salles PV, Roschel H, Gualano B, Sale C, Harris RC, Lancha AH,Artioli GG, 2013. Additive effects of beta-alanine and sodium bicarbonate on upper-body intermittent performance. Amino Acids 45(2): 309-317. https://doi.org/10.1007/s00726-013-1495-z.

Trexler ET, Smith-Ryan AE, Stout JR, Hoffman JR, Wilborn CD, Sale C, et al., 2015. International society of sports nutrition position stand: Beta-Alanine. Journal of the International Society of Sports Nutrition 12: 30. https://doi.org/10.1186/s12970-0150090-y. 
Van Thienen R, Van Proeyen K, Vanden Eynde B, Puype J, Lefere T, Hespel P, 2009. Betaalanine improves sprint performance in endurance cycling. Medicine and Science in Sports and https://doi.org/10.1249/MSS.0b013e31818db708.

Zabala M, Peinado AB, Calderón FJ, Sampedro J, Castillo MJ, Benito PJ, 2011. Bicarbonate ingestion has no ergogenic effect on consecutive all out sprint tests in BMX elite cyclists. European Journal of Applied Physiology 111(12): 3127-3134. https://doi.org/10.1007/s00421-011-1938-8.

Creative Commons licensing terms

Author(s) will retain the copyright of their published articles agreeing that a Creative Commons Attribution 4.0 International License (CC BY 4.0) terms will be applied to their work. Under the terms of this license, no permission is required from the author(s) or publisher for members of the community to copy, distribute, transmit or adapt the article content, providing a proper, prominent and unambiguous attribution to the authors in a manner that makes clear that the materials are being reused under permission of a Creative Commons License. Views, opinions and conclusions expressed in this research article are views, opinions and conclusions of the author(s). Open Access Publishing Group and European Journal of Fitness, Nutrition and Sport Medicine Studies shall not be responsible or answerable for any loss, damage or liability caused in relation to/arising out of conflicts of interest, copyright violations and inappropriate or inaccurate use of any kind content related or integrated into the research work. All the published works are meeting the Open Access Publishing requirements and can be freely accessed, shared, modified, distributed and used in educational, commercial and non-commercial purposes under a Creative Commons Attribution 4.0 International License (CC BY 4.0). 